Article

\title{
Continuous and Intermittent Drying of Rough Rice: Effects on Process Effective Time and Effective Mass Diffusivity
}

\author{
Joan Carlos Alves Pereira ${ }^{1}$, Wilton Pereira da Silva ${ }^{1, *} \mathbb{C}$, Josivanda Palmeira Gomes ${ }^{1}$, \\ Alexandre José de Melo Queiroz ${ }^{1}$, Rossana Maria Feitosa de Figueirêdo ${ }^{1}$ (D), \\ Bruno Adelino de Melo ${ }^{1}$, Ângela Maria Santiago ${ }^{2}$, Antônio Gilson Barbosa de Lima ${ }^{1}$ \\ and Antonio Daniel Buriti de Macedo ${ }^{1}$ \\ 1 Federal University of Campina Grande, Campus I, Paraiba CEP 58429-900, Brazil; \\ joan_carlos21@yahoo.com.br (J.C.A.P.); josivanda@gmail.com (J.P.G.); \\ alexandrejmq@gmail.com (A.J.d.M.Q.); rossanamff@gmail.com (R.M.F.d.F.); b.amelo@yahoo.com (B.A.d.M.); \\ antonio.gilson@ufcg.edu.br (A.G.B.d.L.); daniel_buritt@hotmail.com (A.D.B.d.M.) \\ 2 State University of Paraiba, Paraiba CEP 58431-410, Brazil; angelamariasantiago01@gmail.com \\ * Correspondence: wiltonps@uol.com.br
}

Received: 12 June 2020; Accepted: 6 July 2020; Published: 9 July 2020

check for updates

\begin{abstract}
The choice of the drying process plays a key role in reducing the costs of electricity consumption in the food industry. Thus, this study aimed to evaluate continuous and intermittent drying of rough rice, using empirical and diffusion models to describe the drying kinetics, considering only effective time of operation to compare and evaluate these processes. Experiments were carried out during the month of April 2018, in Campina Grande, Paraiba Brazil, and were conducted with continuous and intermittent drying of rough rice grains (about $20 \mathrm{~g}$, each experiment) using a fixed-bed dryer with constant power, at temperatures of 50 and $70{ }^{\circ} \mathrm{C}$. For the intermittent experiments, the intermittency ratio was $\alpha=2 / 3$ and the drying periods were 10 and $20 \mathrm{~min}$, with intermittency periods of 20 and $40 \mathrm{~min}$, respectively. Comparison between continuous and intermittent drying kinetics indicated reduction in the effective time of all intermittent drying experiments, reaching up to $32.2 \%$, hence promoting energy saving. It was also found that a one-dimensional diffusion model with boundary condition of the first kind properly described all rough rice drying processes and that the effective mass diffusivity is higher in intermittent drying, compared to continuous drying at the same temperature.
\end{abstract}

Keywords: convective drying; intermittency ratio; energy saving; drying models

\section{Introduction}

Among the cereals produced in Brazil and in the world, rice (Oryza sativa L.) is considered a crop of great economic and food importance, being considered as the main food of more than half of the world population, occupying the second place in production and extension of cultivated area, only behind wheat [1]. On the other hand, the waste of an agricultural product (such as fruits, vegetables and grains) is influenced by its moisture content, which affects the quality of the product during its storage [2]. In order to reduce post-harvest waste of agricultural products and increase their shelf life, several techniques are used, such as pasteurization, cooling, osmotic dehydration, among others. Among these techniques, drying is one of the oldest, most simple and most widely used methods in food preservation [3-7]. These techniques aim to reduce the moisture content of the product and, consequently, its water activity, hence avoiding the development of microorganisms and undesirable chemical reactions that can cause deterioration of the product, enabling its safe storage for 
long periods of time. Thus, drying is considered to be a fundamental operation to maintain the quality of products for long periods of time, which is not completely possible for a fresh product.

Intermittent drying has been considered by many authors a more efficient drying method, in terms of energy consumption, improving the quality of the dried material, when compared to continuous drying [8]. The essence of this method is to alternate continuous drying periods with rest periods, allowing the diffusion of moisture from the central region to the surface of the material, as well as the evaporation of surface moisture, to occur more intensely than in continuous drying [5,9]. Therefore, the main reason for using intermittent drying is precisely to minimize the thermal and water gradients inside the material and, consequently, reduce operational costs as well as the possible structural damage to the product during the process, hence improving its final quality [6]. Thus, by using mathematical models, it is possible to accurately describe the drying process of grains and other agricultural products, making it possible to predict the influence of the temperature and moisture of the material, as well as the temperature and humidity of the surrounding air, aiming at an improvement in the energy efficiency of the drying process and quality of the products $[7,10]$.

Intermittent drying of rough rice has been studied by some authors such as Cihan and Ece [11] and Cihan et al. [2]. In reference [11], the authors described continuous and intermittent drying of a thin layer of rough rice, with the elimination of the tempering period, using a two-dimensional diffusion model, with boundary condition of the first kind, in cylindrical coordinates. The authors have concluded that their diffusion model described the drying processes well. However, for the rough rice geometry, it is possible that a one-dimensional model also describes the drying processes well. On the other hand, Cihan et al. [2] described the same experiments as in reference [11], using empirical models. These researchers concluded that Midilli model was the most suitable for the data sets. However, this model involves four parameters and, possibly, a simpler empirical model may also be satisfactory. In this sense, the objective of this article is defined below.

The aim of this study was to compare the continuous and intermittent drying (with intermittency ratio $\alpha=2 / 3$ ) of rough rice at two different temperatures and to describe the processes using empirical and diffusion models to evaluate the saving of effective processing time (and consequently of energy).

\section{Material and Methods}

\subsection{Material and Experimental Procedures}

The study was carried out during the month of April 2018, in the Laboratory of Processing and Storage of Agricultural Products (Laboratório de Armazenamento e Processamento de Produtos Agrícolas, LAPPA) and in the Laboratory of Heat and Mass Transfer (Laboratório de Transferência de Calor e Massa, LTCM) of the Federal University of Campina Grande (Universidade Federal de Campina Grande, UFCG), in the city of Campina Grande, State of Paraiba, Brazil. For the experiment, grains of rough red rice (Oryza sativa L.) were acquired from producers in the municipality of Piancó, Sertão region of Paraíba. The samples were dried in a convective dryer with vertical airflow, developed at UFCG. As additional information, a layout of the dryer is presented in Figure 1a.
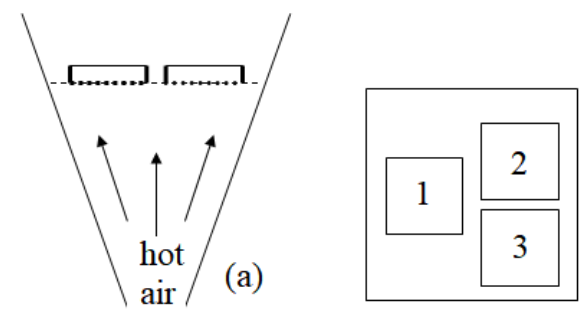

Figure 1. Continuous drying: (a) cross-section of the dryer showing the air flux, the grid and trays for the samples; (b) the positions of the trays on the grid are changed cyclically during the interruptions of the drying process to weigh the grains. 
For each grain, the average diameter was obtained from the mean value between the largest and smallest diameters in the central position, using a digital caliper with resolution of $0.01 \mathrm{~mm}$. Fifty grains were randomly chosen and the measurements were performed. Finally, the average value of diameter for the 50 grains was calculated.

Based on the literature $[2,11]$, the continuous and intermittent drying processes were performed in triplicate, for two temperatures $\left(50\right.$ and $\left.70{ }^{\circ} \mathrm{C}\right)$, and the average drying air speed was $1 \mathrm{~m} \mathrm{~s}^{-1}$. Rough rice grains weighing approximately $20 \mathrm{~g}$ were evenly spread in each one of the three baskets with aluminum screen, forming thin layers, so that the air flowed through the samples. The baskets were initially numbered (from 1 to 3 ) and weighed, and then each set (grains and basket) was also weighed. During the experiments, the moisture content was measured by the gravimetric method using a digital scale with accuracy of $0.001 \mathrm{~g}$.

In the intermittent drying process, each of the three baskets, after weighing, was alternately placed in the dryer, following the time stipulated for the intermittency. While sample number 1 was in the dryer, the other two remained at rest in a desiccator, without silica, at room temperature. After $1 / 3$ of the time of one cycle, sample number 2 was placed in the dryer, at the same time as sample number 1 , after weighing, was placed in the desiccator for the tempering period. After another $1 / 3$ of the cycle time, sample number 3 was placed in the dryer, at the same time as sample number 2 , after weighing, was placed in the desiccator. At the end of one more $1 / 3$ of the cycle time, sample number 3 was taken from the dryer and, after weighing, was placed in the desiccator, while sample number 1 was placed again in the dryer, hence starting a new cycle. As can be seen, in the case of intermittent drying studied in this work, at each instant only one sample remains in the dryer, at the established temperature, while two samples remain in the desiccator, at room temperature. On the other hand, for continuous drying, the three baskets with rough rice grains were taken to the dryer simultaneously, as shown in Figure 1.

In all experiments, mass measurements were performed at regular intervals of 5, 10, 15, 20, 25 and $30 \mathrm{~min}$, and then at intervals of 40,60 and $120 \mathrm{~min}$ until the end of the process, that is, until the grains reached the hygroscopic equilibrium stage, characterized by constant mass. At each specified instant of time, the samples were taken from the dryer, weighed and, in the case of continuous drying, returned to the dryer. When there was no more mass variation in the samples, the equilibrium moisture content was determined. For this, at the end of each drying, the samples were taken to the oven at temperature of $105^{\circ} \mathrm{C}$ and left there for $24 \mathrm{~h}$, for the measurement of dry mass.

In total, six drying experiments were carried out $\left(E_{1}\right.$ to $\left.E_{6}\right)$, four of intermittent drying, with intermittency ratio of $\alpha=2 / 3$, and two of continuous drying. This study was conducted adopting the definition of intermittency ratio $(\alpha)$ given by reference [5], defined as the ratio between the tempering period and the total time of one cycle: $\alpha=t_{\text {out }} /\left(t_{\text {in }}+t_{\text {out }}\right)$, where $t_{\text {in }}+t_{\text {out }}$ corresponds to the total time of one cycle, and the terms " $\mathrm{t}_{\mathrm{in}}$ " and " $\mathrm{t}_{\text {out }}$ " represent the times of the samples in and out of the dryer, respectively. Information about each of the experiments is presented in Table 1.

Table 1. Parameters for each experiment of rough rice drying.

\begin{tabular}{ccccc}
\hline Experiment & Drying & $\mathbf{t}_{\text {in }}(\mathbf{m i n})$ & $\mathbf{t}_{\text {out }}(\mathbf{m i n})$ & $\mathbf{T}\left({ }^{\circ} \mathbf{C}\right)$ \\
\hline $\mathrm{E}_{1}$ & Continuous & - & - & 50 \\
$\mathrm{E}_{2}$ & Intermittent & 10 & 20 & 50 \\
$\mathrm{E}_{3}$ & Intermittent & 20 & 40 & 50 \\
\hline $\mathrm{E}_{4}$ & Continuous & - & - & 70 \\
$\mathrm{E}_{5}$ & Intermittent & 10 & 20 & 70 \\
$\mathrm{E}_{6}$ & Intermittent & 20 & 40 & 70 \\
\hline
\end{tabular}

$t_{\text {in }}$ and $t_{\text {out }}$ represent the times of the samples in and out of the dryer; $T$ is temperature. 
Once the data of moisture content on a dry basis (d.b.) were obtained, the moisture ratio $\left(\bar{X}^{*}\right)$ at each instant was determined using the following expression:

$$
\bar{X}^{*}=\frac{\bar{X}-X_{\mathrm{eq}}}{X_{i}-X_{\mathrm{eq}}}
$$

where: $\bar{X}$-Average moisture content of the product (d.b.); $\mathrm{X}_{\mathrm{eq}}$-Equilibrium moisture content of the product (d.b.); $\mathrm{X}_{\mathrm{i}}$-Initial moisture content of the product (d.b.).

\subsection{Description of Drying Kinetics: Empirical Models}

For the mathematical fit of the drying curves, six empirical equations frequently used in the literature to describe the drying kinetics of agricultural products were fitted to the experimental data sets. These empirical equations are presented in Table 2.

Table 2. Empirical models used to predict drying kinetics.

\begin{tabular}{clc}
\hline Model & \multicolumn{1}{c}{ Equation } & Equation \\
\hline Henderson and Pabis & $\overline{\mathrm{X}}^{*}=\operatorname{aexp}(-\mathrm{bt})$ & $(2)$ \\
Lewis & $\overline{\mathrm{X}}^{*}=\exp (-\mathrm{at})$ & $(3)$ \\
Page & $\overline{\mathrm{X}}^{*}=\exp (-\mathrm{at} \mathrm{b})$ & $(4)$ \\
Peleg & $\overline{\mathrm{X}}^{*}=1-\mathrm{t} /(\mathrm{a}+\mathrm{bt})$ & $(6)$ \\
Silva et alii & $\overline{\mathrm{X}}^{*}=\exp \left(-\mathrm{at}-\mathrm{bt}^{1 / 2}\right)$ & $(7)$ \\
Wang and Singh & $\overline{\mathrm{X}}^{*}=1+\mathrm{at}+\mathrm{bt}^{2}$ &
\end{tabular}

To describe the intermittent drying kinetics, the data related to the tempering periods were eliminated, and only the data referring to the time in which the samples remained inside the dryer (effective time of operation) were analyzed [10]. With this strategy, intermittent drying could be analyzed as "pseudo-continuous" drying [11]. The description of drying kinetics through empirical models was performed using LAB Fit Curve Fitting Software (developed in Federal University of Campina Grande, Paraiba, Brazil) [12].

\subsection{Description of Drying Kinetics: Diffusion Model}

In addition to empirical models, water migration inside rough rice grains was also described by a diffusion model (characterized below), fitted to the experimental data. In this case, each rice grain was considered to have the geometric shape of an infinite cylinder. To analytically solve the diffusion equation by the separation of variables, it was assumed that the boundary condition could be considered as that of the first kind. In addition, as the initial moisture content of the grains was relatively low, when compared to fruits and vegetables, it was assumed that their volumetric shrinkage during the process could be disregarded. It was also assumed that liquid diffusion was the only mechanism of water transport inside the grains, and also that the initial distribution of moisture was uniform. Finally, the effective mass diffusivity was considered constant throughout the process; and the grains were considered as a homogeneous and isotropic medium.

Thus, for a homogeneous infinite cylinder with radius $\mathrm{R}$, with uniformly distributed initial moisture content, $X_{i}$, with equilibrium moisture content $X_{\text {eq }}$, the solution $X(r, t)$ of the one-dimensional diffusion equation in cylindrical coordinates is expressed as $[4,13,14]$ :

$$
X(r, t)=X_{e q}+\left(X_{i}-X_{e q}\right) \sum_{n=1}^{\infty} A_{n} J_{0}\left(\frac{\mu_{n} r}{R}\right) \exp \left(-\mu_{n}^{2} \frac{D}{R^{2}} t\right)
$$


where the parameter $A_{n}$ is given by:

$$
\mathrm{A}_{\mathrm{n}}=\frac{2}{\mu_{\mathrm{n}} \mathrm{J}_{1}\left(\mu_{\mathrm{n}}\right)}
$$

where $\mu_{\mathrm{n}}$ are roots obtained through the following characteristic equation:

$$
\mathrm{J}_{0}\left(\mu_{\mathrm{n}}\right)=0
$$

In Equations (8)-(10), $\mathrm{J}_{0}$ and $\mathrm{J}_{1}$ are the first-kind Bessel functions of orders 0 and 1, respectively, and $\mu_{\mathrm{n}}$ are the roots of the first-kind Bessel function of order 0 . In Equation (8), $X(r, t)$ is the moisture content (d.b.) at a position $r$ with respect to the central axis of the cylinder, at an instant $t, X_{\text {eq }}$ is the moisture content for $t \rightarrow \infty$; $X_{i}$ is the moisture content for $t=0$, and $D$ is the effective mass diffusivity.

The average value of the moisture content, at an instant $t$, is defined as

$$
\bar{X}(t)=\frac{1}{V} \int x(r, t) d V,
$$

where $\mathrm{V}$ is the volume of the cylinder.

For the boundary condition of the first kind, the solution of the diffusion equation with average value $\bar{X}(t)$ in a cylindrical solid at an instant $t$ is obtained by substituting Equation (8) in Equation (11), resulting in:

$$
\bar{X}(t)=X_{e q}+\left(X_{i}-X_{e q}\right) \sum_{n=1}^{\infty} \frac{4}{\mu_{n}^{2}} \exp \left(-\mu_{n}^{2} \frac{D}{R^{2}} t\right) .
$$

Determination of effective mass diffusivity and simulation of drying kinetics through the diffusion model presented above were performed using the program Prescribed Adsorption-Desorption [15], which uses the first 200 terms of the infinite series given by Equation (12) and also by Equation (8).

\section{Results and Discussion}

\subsection{Experimental Results}

The mean value of the initial moisture content $\left(X_{i}\right)$ of rice grains was 0.275 (d.b.), and the mean value of radius was $1.37 \mathrm{~mm}$. The mean values of equilibrium moisture content, $X_{\text {eq, }}$, obtained for each experiment at $50{ }^{\circ} \mathrm{C}$ were $0.072,0.084$ and 0.066 (d.b.) for continuous drying, intermittent drying with $\mathrm{t}_{\mathrm{in}}=10 \mathrm{~min}$ and intermittent drying with $\mathrm{t}_{\text {in }}=20 \mathrm{~min}$, respectively; and $0.036,0.043$ and 0.031 (d.b.) for the same drying processes at $70^{\circ} \mathrm{C}$. Thus, it can be noted that the equilibrium moisture content was lower, on average, for the higher drying temperature, as expected, and also as already observed for other seeds, such as those of crambe [16].

\subsection{Results Obtained by Empirical Models}

Using LAB Fit software, it was possible to summarize the results obtained for continuous drying using empirical models as presented in Table 3, which shows all proposed models and their respective parameters. The quality of fit of the mathematical models to the experimental data was evaluated using the statistical indicators coefficient of determination $\left(R^{2}\right)$ and chi-square $\left(\chi^{2}\right)$, also presented in Table 3. 
Table 3. Parameters of the different mathematical models for continuous drying at temperatures of 50 and $70^{\circ} \mathrm{C}$.

\begin{tabular}{|c|c|c|c|c|c|}
\hline \multirow{2}{*}{ Models } & \multirow{2}{*}{$\mathrm{T}\left({ }^{\circ} \mathrm{C}\right)$} & \multicolumn{2}{|c|}{ Parameters } & \multirow{2}{*}{$\mathbf{R}^{2}$} & \multirow{2}{*}{$x^{2}$} \\
\hline & & $\mathbf{a}$ & b & & \\
\hline \multirow{2}{*}{ Henderson and Pabis } & 50 & 0.8580 & $0.8584 \times 10^{-2}$ & 0.976366 & $0.4412 \times 10^{-1}$ \\
\hline & 70 & 0.8351 & $0.1587 \times 10^{-1}$ & 0.960002 & $0.7726 \times 10^{-1}$ \\
\hline \multirow{2}{*}{ Lewis } & 50 & $0.1106 \times 10^{-1}$ & - & 0.988969 & 0.1287 \\
\hline & 70 & $0.2100 \times 10^{-1}$ & - & 0.981073 & 0.1440 \\
\hline \multirow{2}{*}{ Page } & 50 & $0.4736 \times 10^{-1}$ & 0.6704 & 0.998382 & $0.2720 \times 10^{-2}$ \\
\hline & 70 & $0.9616 \times 10^{-1}$ & 0.6050 & 0.997275 & $0.4174 \times 10^{-2}$ \\
\hline \multirow{2}{*}{ Peleg } & 50 & $0.5405 \times 10^{2}$ & 0.9692 & 0.993470 & $0.1352 \times 10^{-1}$ \\
\hline & 70 & $0.2588 \times 10^{2}$ & 0.9947 & 0.996409 & $0.5991 \times 10^{-2}$ \\
\hline \multirow{2}{*}{ Silva et alii } & 50 & $0.3873 \times 10^{-2}$ & $0.6339 \times 10^{-1}$ & 0.998172 & $0.3063 \times 10^{-2}$ \\
\hline & 70 & $0.3911 \times 10^{-2}$ & 0.1155 & 0.995077 & $0.7497 \times 10^{-2}$ \\
\hline \multirow{2}{*}{ Wang and Singh } & 50 & $-0.7967 \times 10^{-2}$ & $0.1679 \times 10^{-4}$ & 0.948383 & 0.2788 \\
\hline & 70 & $-0.1002 \times 10^{-1}$ & $0.2260 \times 10^{-4}$ & 0.847930 & 0.8101 \\
\hline
\end{tabular}

T: temperature; $a$ and $b$ are fitting parameters; $\mathbf{R}^{2}$ is determination coefficient; $\chi^{2}$ is chi-square.

According to the statistical indications of Table 3, Page, Silva et alii and Peleg were the models that best fitted to the experimental data. Thus, these models can be used to predict the drying kinetics of rough rice grains, especially the Page model, which had the higher coefficient of determination $(>0.997)$ and lower chi-square $(<0.005)$ at both temperatures.

For continuous drying, the graphs in Figure 2 were obtained using the Page model. After the analysis of drying kinetics, the time limit of effective operation was established as $360 \mathrm{~min}$ in all experiments.

(a)

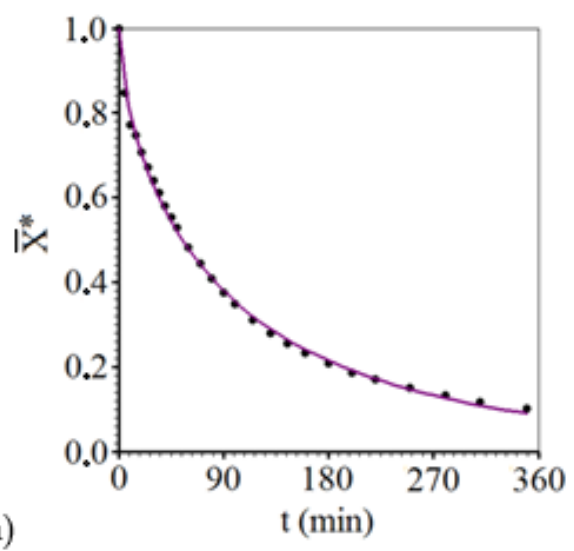

(b)

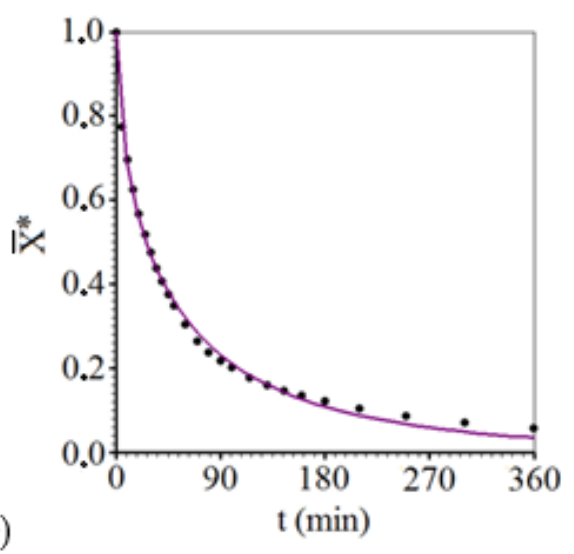

Figure 2. Continuous drying kinetics described by the Page model at temperatures of: (a) $50{ }^{\circ} \mathrm{C}$; (b) $70{ }^{\circ} \mathrm{C}$.

As supplementary information, for continuous drying the parameters of Page model, including the uncertainties can be written as follows: (1) at $50^{\circ} \mathrm{C}, \mathrm{a}=0.0474 \pm 0.0017, \mathrm{~b}=0.670 \pm 0.008$; (2) at $70{ }^{\circ} \mathrm{C}, \mathrm{a}=0.0962 \pm 0.0042, \mathrm{~b}=0.605 \pm 0.011$.

To describe the intermittent drying processes, the tempering periods were eliminated. Thus, only the effective time, i.e., the time the product remained inside the dryer, was considered, as if each intermittent drying period were a "pseudo-continuous" drying process. The main results obtained are given in Table 4 for the models of Page, Silva et alii and Peleg. 
Table 4. Parameters of the different mathematical models for intermittent drying at temperatures of 50 and $70^{\circ} \mathrm{C}$.

\begin{tabular}{|c|c|c|c|c|c|c|}
\hline & \multirow{2}{*}{ Models } & \multirow{2}{*}{$\mathrm{T}\left({ }^{\circ} \mathrm{C}\right)$} & \multicolumn{2}{|c|}{ Parameters } & \multirow{2}{*}{$\mathbf{R}^{2}$} & \multirow{2}{*}{$x^{2}$} \\
\hline & & & $\mathbf{a}$ & b & & \\
\hline \multirow{6}{*}{$\begin{array}{l}\text { Intermittent } \\
\mathrm{t}_{\mathrm{in}}=10 \mathrm{~min}\end{array}$} & \multirow{2}{*}{ Page } & 50 & $0.5338 \times 10^{-1}$ & 0.7000 & 0.997644 & $0.1383 \times 10^{-1}$ \\
\hline & & 70 & 0.1009 & 0.6404 & 0.998749 & $0.5948 \times 10^{-2}$ \\
\hline & \multirow{2}{*}{ Peleg } & 50 & $0.3997 \times 10^{2}$ & 0.9361 & 0.997334 & $0.1685 \times 10^{-1}$ \\
\hline & & 70 & $0.2114 \times 10^{2}$ & 0.9558 & 0.997417 & $0.1407 \times 10^{-1}$ \\
\hline & \multirow{2}{*}{ Silva et alii } & 50 & $0.5938 \times 10^{-2}$ & 0.0722 & 0.995575 & $0.2670 \times 10^{-1}$ \\
\hline & & 70 & $0.6753 \times 10^{-2}$ & 0.1236 & 0.997059 & $0.1454 \times 10^{-1}$ \\
\hline \multirow{6}{*}{$\begin{array}{l}\text { Intermittent } \\
t_{\text {in }}=20 \mathrm{~min}\end{array}$} & \multirow{2}{*}{ Page } & 50 & $0.4002 \times 10^{-1}$ & 0.7358 & 0.997988 & $0.1267 \times 10^{-1}$ \\
\hline & & 70 & $0.8696 \times 10^{-1}$ & 0.6691 & 0.997248 & $0.1393 \times 10^{-1}$ \\
\hline & \multirow{2}{*}{ Peleg } & 50 & $0.5095 \times 10^{2}$ & 0.9140 & 0.997187 & $0.1934 \times 10^{-1}$ \\
\hline & & 70 & $0.2301 \times 10^{2}$ & 0.9494 & 0.995698 & $0.2158 \times 10^{-1}$ \\
\hline & \multirow{2}{*}{ Silva et alii } & 50 & $0.5995 \times 10^{-2}$ & 0.0566 & 0.996481 & $0.2278 \times 10^{-1}$ \\
\hline & & 70 & $0.8142 \times 10^{-2}$ & 0.1079 & 0.995543 & $0.2396 \times 10^{-1}$ \\
\hline
\end{tabular}

Figure 3 presents the simulations of the intermittent (pseudo-continuous) drying kinetics, with cycles involving the time of $10 \mathrm{~min}$ inside the dryer $\left(t_{\text {in }}=10 \mathrm{~min}\right)$ and $20 \mathrm{~min}$ outside the drying $\left(t_{\text {out }}=20 \mathrm{~min}\right)$, in the desiccator. These kinetic processes were also obtained using the Page model for temperatures of 50 and $70^{\circ} \mathrm{C}$.
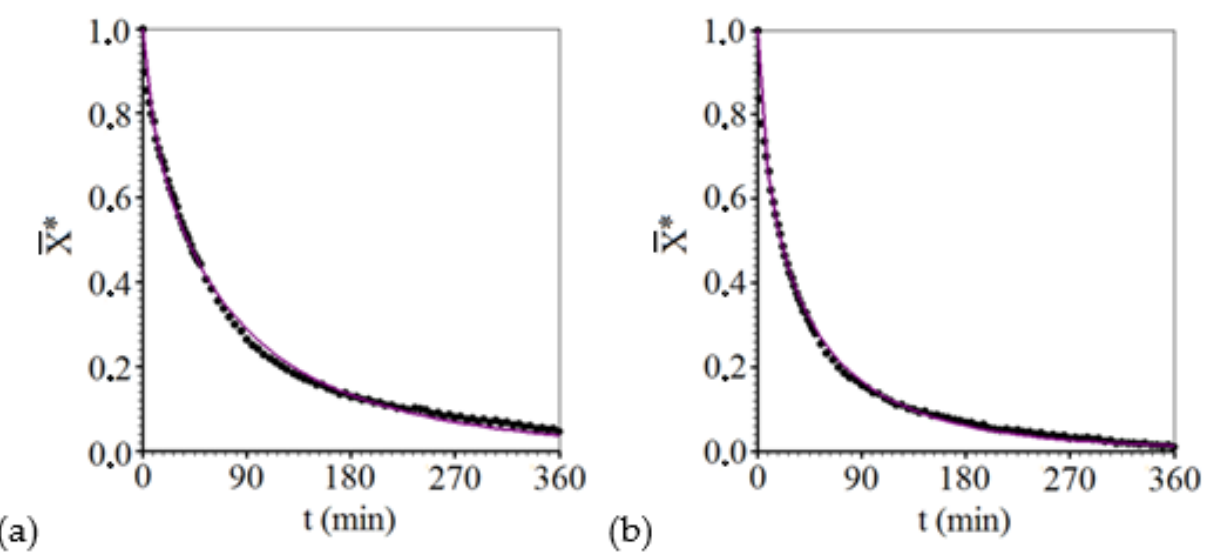

Figure 3. Intermittent drying kinetics with $\mathrm{t}_{\text {in }}=10 \mathrm{~min}$, described by the Page model at temperatures of: (a) $50{ }^{\circ} \mathrm{C}$; (b) $70{ }^{\circ} \mathrm{C}$.

For intermittent drying, with $t_{i n}=10 \mathrm{~min}$, the parameters of the Page model, including the uncertainties, can be written as follows: (1) at $50{ }^{\circ} \mathrm{C}, \mathrm{a}=0.0534 \pm 0.0014, \mathrm{~b}=0.700 \pm 0.006$; (2) at $70{ }^{\circ} \mathrm{C}$, $\mathrm{a}=0.1009 \pm 0.0017, \mathrm{~b}=0.6404 \pm 0.0041$.

Figure 4 presents the simulations of the intermittent (pseudo-continuous) drying kinetics with cycles involving the time of $20 \mathrm{~min}\left(\mathrm{t}_{\mathrm{in}}=20 \mathrm{~min}\right)$ in the dryer and $40 \mathrm{~min}\left(\mathrm{t}_{\text {out }}=40 \mathrm{~min}\right.$ ) outside the dryer, in the desiccator. As in the previous cases, these kinetic processes, at temperatures of 50 and $70{ }^{\circ} \mathrm{C}$, were obtained using the Page model. 

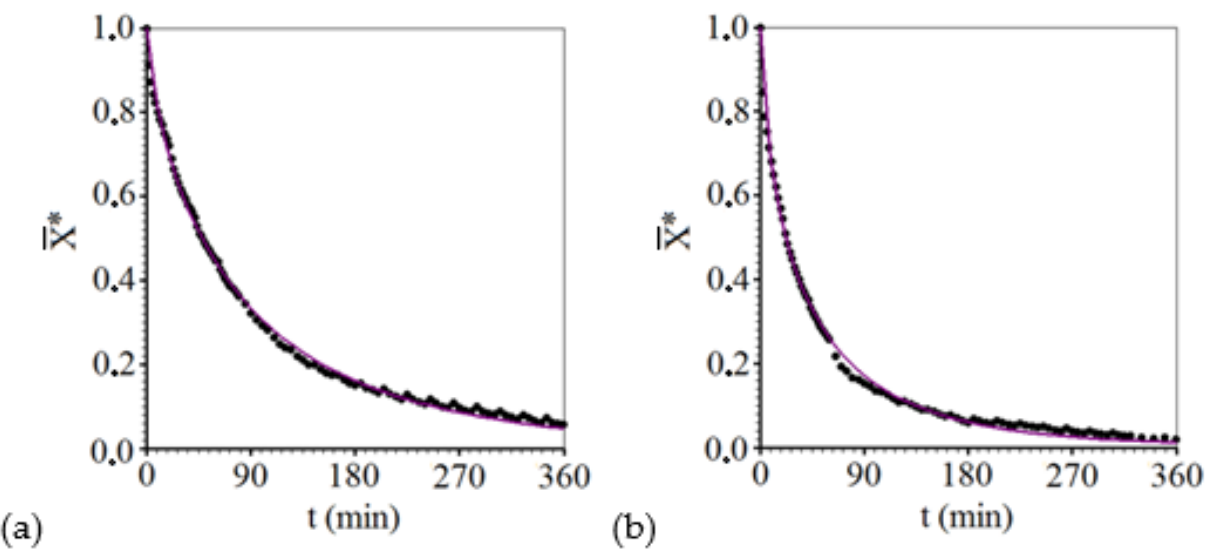

Figure 4. Intermittent drying kinetics with $\mathrm{t}_{\mathrm{in}}=20 \mathrm{~min}$, described by the Page model at temperatures of: (a) $50{ }^{\circ} \mathrm{C}$; (b) $70{ }^{\circ} \mathrm{C}$.

Once the Page model has been chosen to represent the intermittent drying kinetics, with $t_{\text {in }}=$ $20 \mathrm{~min}$, the parameters of this equation, including the uncertainties, can be written as follows: (1) at $50{ }^{\circ} \mathrm{C}, \mathrm{a}=0.0400 \pm 0.0009, \mathrm{~b}=0.736 \pm 0.005 ;(2)$ at $70{ }^{\circ} \mathrm{C}, \mathrm{a}=0.0870 \pm 0.0023, \mathrm{~b}=0.669 \pm 0.007$.

As observed for the continuous drying, the results obtained with the three empirical models mentioned showed good fits to the experimental data of intermittent drying with both $t_{\text {in }}=10$ and $t_{\text {in }}$ $=20 \mathrm{~min}$. Again, the Page model had the best results in the description of the process at both 50 and $70^{\circ} \mathrm{C}$, as can be seen in Table 4 . The Page model is generally used with success in describing the drying kinetics of various agricultural products. Morais et al. [17], Santos and Oliveira [18] and Benseddik el al. [19] have also used this model to describe the continuous drying of beans, rice and pumpkin grains, respectively. These authors also, obtained coefficients of determination higher than 0.99 .

A very interesting aspect regarding Figures 3 and 4 are the rehydration processes that can be visualized in these figures, especially in Figure 4. A possible cause for this effect that is so noticeable, particularly in the final part of each intermittent drying, was the absence of silica in the desiccator, meaning that the saving of effective time (and consequently of energy) might have been even greater than the saving obtained in the present study. On the other hand, in order to make a comparison with the drying methods, Figure 5 presents the three kinetic processes (continuous, intermittent with $t_{\text {in }}=$ $10 \mathrm{~min}$ and intermittent with $\mathrm{t}_{\mathrm{in}}=20 \mathrm{~min}$ ) for each temperature, using the Page model.
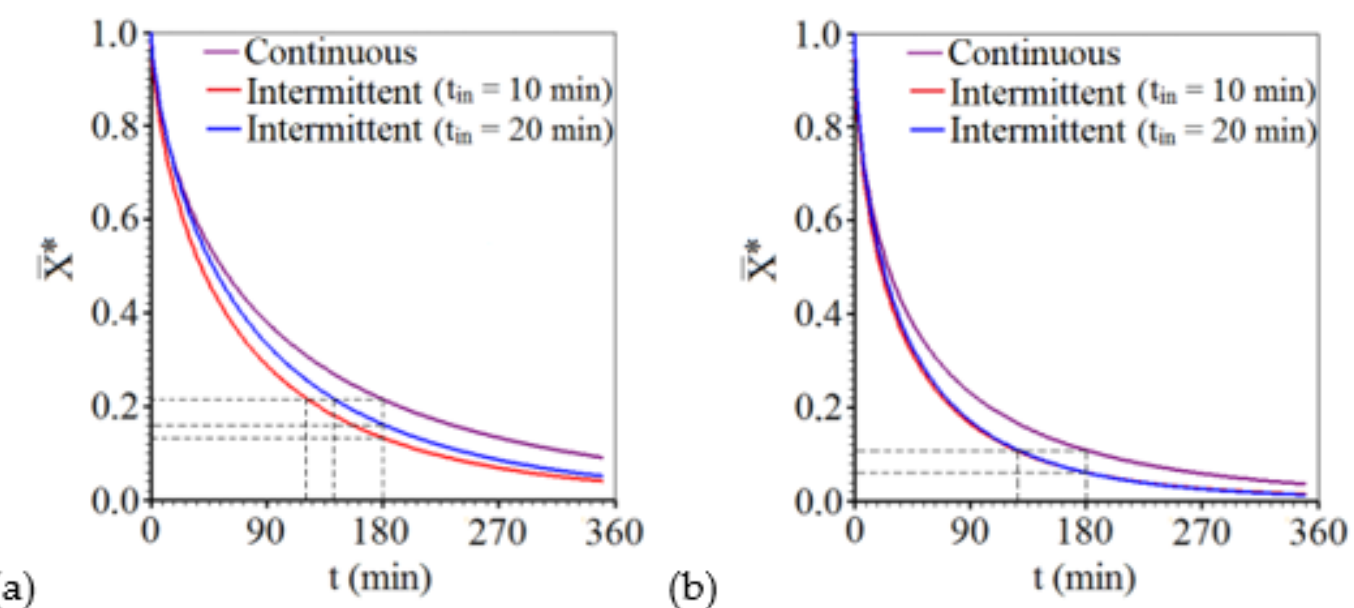

Figure 5. Superposition of rice drying kinetics described by the Page model for drying air temperatures of: (a) $50{ }^{\circ} \mathrm{C}$; (b) $70{ }^{\circ} \mathrm{C}$. 
Figure 5 shows that the intermittent drying kinetic processes are significantly different from the continuous drying kinetics for the two temperatures studied. In the intermittent drying processes, rice grains lost more moisture when compared to the corresponding continuous drying, for the same instant. As an example, in Figure $5 \mathrm{a}$, at $50{ }^{\circ} \mathrm{C}$, it can be observed that the time required for the rice to reach the moisture ratio of approximately 0.22 was $180 \mathrm{~min}$ for continuous drying and only about $122 \mathrm{~min}$ for intermittent drying with $\mathrm{t}_{\mathrm{in}}=10 \mathrm{~min}$. This means an effective time saving of about $58 \mathrm{~min}$, which corresponds to a reduction of $32.2 \%$ in the effective drying time and, consequently, in energy consumption, since the dryer operates at constant power. Also, in relation to Figure $5 \mathrm{a}$, it can be noted that for intermittent drying with $t_{i n}=20 \mathrm{~min}$, the reduction of effective time was about $20 \%$, compared to continuous drying. These reductions in effective time with the use of intermittency are possible because, during the tempering period, there is diffusion of moisture from the central part to the surface of the product, favoring the homogenization of its moisture content and temperature. Consequently, the thermal and water gradients generated during the drying period tend to decrease during the tempering period, avoiding cracks and fissures on the grains [6,20-22]. This effect is responsible for accelerating the drying process and, consequently, reducing energy consumption. On the other hand, Yang et al. [23] dried Chinese cabbage seeds with different intermittency ratios, with temperature of $40{ }^{\circ} \mathrm{C}$ and drying air speed of $1 \mathrm{~m} \mathrm{~s}^{-1}$. According to the results of these authors, the energy saving obtained was $48.1 \%$ compared to continuous drying.

Also with regard to Figure $5 \mathrm{a}$, it can be noted that there was a significant difference between the curves of the two intermittent drying processes and that drying with $t_{\text {in }}=10$ min showed greater saving of effective time than drying with $t_{i n}=20 \mathrm{~min}$. At this point, it is interesting to note that, although the intermittency ratio $(\alpha=2 \beta)$ was the same for the intermittent drying processes, the tempering period influenced the reduction in the effective drying time. Recently, Silva et al. [7] conducted experiments with continuous and intermittent drying of apple slices with intermittency ratio $\alpha=2 \beta$. These researchers also found that, considering only the effective time of operation, the intermittent drying kinetics with $t_{i n}=15 \mathrm{~min}$ had better results when compared to the longer drying periods, given by $t_{\text {in }}=30 \mathrm{~min}$ and $t_{\text {in }}=60 \mathrm{~min}$, although all drying processes had the same intermittency ratio.

Figure $5 \mathrm{~b}$ shows that, for $70^{\circ} \mathrm{C}$, considering only the effective time of operation, the intermittent drying kinetics with $t_{\text {in }}=10 \mathrm{~min}$ is similar to that with $t_{\text {in }}=20 \mathrm{~min}$ and, therefore, intermittent drying processes produced similar effects to one another, but considerably better than those of continuous drying. As an example, for a moisture ratio of about 0.11 , there are times of about $126 \mathrm{~min}$ for intermittent drying and $180 \mathrm{~min}$ for continuous drying, indicating a reduction of $30.0 \%$. Obviously, it is also possible to observe that, for a given drying air speed, the moisture ratio decreased faster with the temperature increase from 50 to $70^{\circ} \mathrm{C}$, as expected: the higher the temperature, the faster the drying process $[24,25]$.

\subsection{Results Obtained by the Diffusion Model}

In this study, a diffusion model with boundary condition of the first kind was also used to describe the continuous and intermittent drying of rough rice grains. For this model, a single parameter must be determined in the process description: effective mass diffusivity, $\mathrm{D}$.

The results obtained using the Prescribed Adsorption-Desorption software (Federal University of Campina Grande, Paraiba, Brazil) [15], which uses the analytical solution of the diffusion equation with a boundary condition of the first kind, are summarized in Table 5, which also presents the statistical indicators related to this model. 
Table 5. Results obtained for the simulations of drying using the diffusion model with a boundary condition of the first kind.

\begin{tabular}{ccccc}
\hline Drying & $\mathbf{T}\left({ }^{\circ} \mathbf{C}\right)$ & $\mathbf{D}\left(\mathbf{m}^{\mathbf{2}} \mathbf{~ m i n}^{-1}\right)$ & $\mathbf{R}^{\mathbf{2}}$ & $\mathbf{x}^{\mathbf{2}}$ \\
\hline Continuous & & $2.0949 \times 10^{-9}$ & 0.996184 & $6.5744 \times 10^{-2}$ \\
Intermittent $\left(\mathrm{t}_{\text {in }}=10 \mathrm{~min}\right)$ & 50 & $2.9817 \times 10^{-9}$ & 0.991756 & $4.9611 \times 10^{-2}$ \\
Intermittent $\left(\mathrm{t}_{\text {in }}=20 \mathrm{~min}\right)$ & & $2.5149 \times 10^{-9}$ & 0.992354 & $5.9541 \times 10^{-2}$ \\
\hline Continuous & & $4.0694 \times 10^{-9}$ & 0.991151 & $2.2129 \times 10^{-2}$ \\
Intermittent $\left(\mathrm{t}_{\text {in }}=10 \mathrm{~min}\right)$ & 70 & $5.3609 \times 10^{-9}$ & 0.994840 & $4.4117 \times 10^{-2}$ \\
Intermittent $\left(\mathrm{t}_{\text {in }}=20 \mathrm{~min}\right)$ & & $5.1088 \times 10^{-9}$ & 0.993616 & $4.3745 \times 10^{-2}$ \\
\hline
\end{tabular}

D: effective mass diffusivity.

By comparing the statistical indicators of the fits of empirical models (Tables 3 and 4) and diffusion model (Table 5) to the experimental data, it can be observed that they are equivalent, in practical terms. Nevertheless, it should be emphasized that, in the diffusion model, only one fitting parameter is determined, while in the empirical models analyzed, two parameters are determined. Thus, it is unnecessary to present the graphs of the fits obtained using the diffusion model, because they are similar to the corresponding figures already presented using the empirical models (Figures 2-5). On the other hand, an inspection of Table 5 makes it possible to restate that the diffusion model with a boundary condition of the first kind actually had good statistical indicators, as already mentioned. Thus, the diffusion model can be considered adequate to describe the continuous and intermittent drying of rough rice. Physically, this model indicates that the external surface of the grain comes into equilibrium with the drying air early in the process, so there is no resistance to water flow on that surface. Results available in the literature indicate that the boundary condition of the first kind is actually widely used to describe moisture transport in most grains $[3,17,26]$. Also, the values obtained for the effective diffusivity of rough rice are compatible with values obtained for biological products, between $10^{-10}$ and $10^{-8} \mathrm{~m}^{2} \mathrm{~min}^{-1}$, available in the literature $[3,27]$.

Table 5 shows that the values of effective mass diffusivity at $50{ }^{\circ} \mathrm{C}$ are equal to $2.0949 \times 10^{-9} \mathrm{~m}^{2}$ $\mathrm{min}^{-1}$ (continuous drying), $2.9817 \times 10^{-9} \mathrm{~m}^{2} \mathrm{~min}^{-1}$ (intermittent drying with $\mathrm{t}_{\mathrm{in}}=10 \mathrm{~min}$ ) and 2.5149 $\times 10^{-9} \mathrm{~m}^{2} \mathrm{~min}^{-1}$ (intermittent drying with $\mathrm{t}_{\mathrm{in}}=20 \mathrm{~min}$ ). Therefore, it is possible to observe through the obtained values that, indeed, the intermittency significantly increases the diffusivity of the process, compared to continuous drying. Among the intermittent drying processes at $50{ }^{\circ} \mathrm{C}$, the one with $t_{\text {in }}=$ $10 \mathrm{~min}$ has the highest effective mass diffusivity, which results in saving of effective time, as can be observed in Figure 5a. Regarding the temperature of $70{ }^{\circ} \mathrm{C}$, Table 5 presents similar values of mass diffusivity for the two intermittent drying processes, but significantly higher than the diffusivity of continuous drying, which can also be noted through Figure $5 b$.

As the diffusion model had statistical indicators equivalent to those of empirical models, it should be, only for this reason, the one recommended to describe the drying because this model involves the determination of only one parameter (effective mass diffusivity), while the best empirical models presented in this article involve two. However, there is still a much stronger reason for recommending the diffusion model. With this model, one can predict the spatial distribution of moisture at any instant, both for continuous drying and for intermittent drying in which only the effective time is considered. As an example, for the temperature of $50{ }^{\circ} \mathrm{C}$, Figure 6 presents the distribution of moisture in a circular section of the infinite cylinder for the instant $\mathrm{t}=66 \mathrm{~min}$, both for continuous drying and for intermittent drying $\left(\mathrm{t}_{\mathrm{in}}=10 \mathrm{~min}\right)$. 


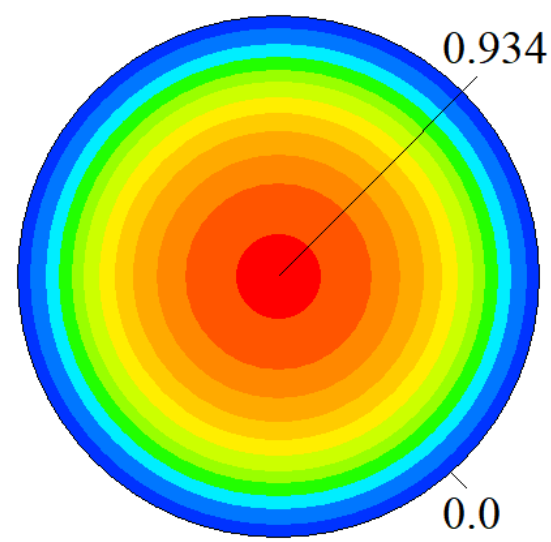

(a)

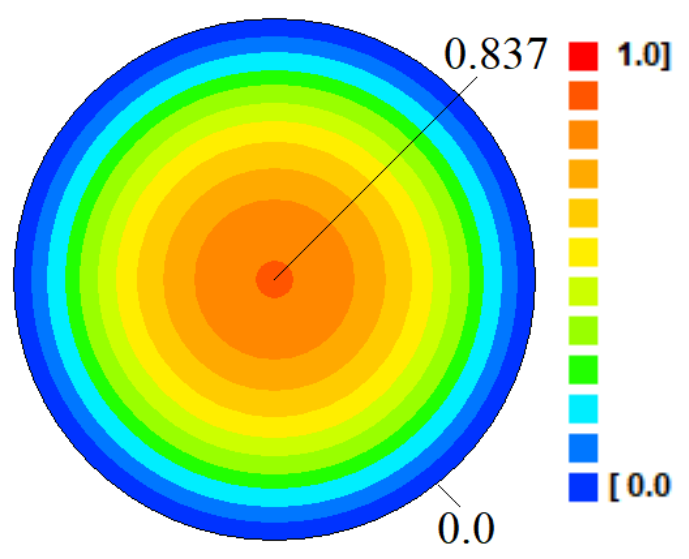

(b)

Figure 6. Distribution of moisture in the circular sections of rice grains, predicted by the diffusion model at $\mathrm{t}=66 \mathrm{~min}$, at $50^{\circ} \mathrm{C}$ : (a) Continuous drying; (b) Intermittent drying $\left(\mathrm{t}_{\text {in }}=10 \mathrm{~min}\right)$.

For the instant of $66 \mathrm{~min}$, at $50{ }^{\circ} \mathrm{C}$, the average moisture ratios for continuous drying and intermittent drying $\left(t_{\text {in }}=10 \mathrm{~min}\right.$ ) were estimated by the diffusion model, resulting in 0.466 and 0.389 (d.b.), respectively. On the other hand, Figure 6 was obtained using Equation (8), after determining the values of effective mass diffusivity (by optimization), using Equation (12). Through Figure 6 it is possible to observe that, for continuous drying, the moisture ratio ranges from 0.0 (surface) to 0.934 (center), while for intermittent drying the variation is from 0.0 (surface) to 0.837 (center). This means that the moisture gradients inside the grain for the case of continuous drying are greater than the corresponding gradients for intermittent drying. These water gradients (and also thermal gradients) are those that generate tensions which can damage the product, and these gradients can, as observed, be determined through the diffusion model presented in this article [3].

As a result of this study, intermittent drying has significant advantages over continuous drying. However, there is a possibility that a large mass of grains may behave differently than a small, thin-layered sample, such as those used in the experiments of this article. In this sense, more research may be needed to study the drying of large masses of rough rice. It is interesting to observe that, in the case of a large mass of grains, intermittent drying can lead to a greater occupation of the drying facilities. Thus, although energy saving is very important, the occupation of drying facilities can be a limiting factor because, in this case, not all production could be dried in a timely manner.

\section{Conclusions}

Six drying experiments were carried out at two temperatures $\left(50{ }^{\circ} \mathrm{C}\right.$ and $\left.70{ }^{\circ} \mathrm{C}\right)$, involving samples of about $20 \mathrm{~g}$ of rough rice. For each temperature, a continuous drying experiment and two intermittent ones were performed, with intermittency ratio equal to $2 / 3$. The two experiments of intermittent drying at each temperature involved drying periods $\left(t_{i n}\right)$ of 10 and $20 \mathrm{~min}$. The analysis of the results allowed us to conclude the following.

(1) Among the empirical models tested, Page, and also the models of Peleg and Silva et alii fit well to the experimental data, especially Page's, which was chosen to describe the continuous and intermittent drying kinetics of rough rice.

(2) Considering all drying processes, the greatest saving of effective time was obtained for the intermittent drying experiment with $t_{\text {in }}=10 \mathrm{~min}$, at $50{ }^{\circ} \mathrm{C}$, which resulted in a $32.2 \%$ reduction of effective drying time compared to the continuous drying.

(3) It was found that not only is the intermittency ratio important for the reduction of the effective drying time, but also the tempering period, which considerably affected the drying kinetics of rice grains at the temperature of $50{ }^{\circ} \mathrm{C}$. For the temperature of $70{ }^{\circ} \mathrm{C}$, the tempering periods practically 
did not influence the intermittent drying kinetics, and both reduced the effective time of operation by about $30.0 \%$ in comparison to the continuous drying.

(4) The one-dimensional diffusion model with boundary condition of the first kind adequately described the continuous and intermittent drying of rough rice. It was observed that the diffusion coefficient increases with the application of intermittency during drying. This effect, of increase in effective mass diffusivity, was responsible for accelerating the drying process and, consequently, reducing the energy consumption.

Author Contributions: Data curation, J.C.A.P.; Formal analysis, W.P.d.S.; Investigation, W.P.d.S. and A.J.d.M.Q.; Methodology, R.M.F.d.F. and A.G.B.d.L.; Supervision, J.P.G., B.A.d.M. and A.D.B.d.M.; Validation, Â.M.S. All authors have read and agreed to the published version of the manuscript.

Funding: Conselho Nacional de Desenvolvimento Cientifico e Technológico 301708/2019-3; PQ.

Acknowledgments: The second author would like to thank CNPq (Conselho Nacional de Desenvolvimento Científico e Tecnológico) for supporting this study and for his research grant (Process Number 301708/2019-3; PQ-1A).

Conflicts of Interest: On behalf of all authors, the corresponding author states that there is no conflict of interest.

\section{References}

1. FAO. Food and Agriculture Organization of the United Nations. FAOSTAT. 2018. Available online: http://www.fao.org/faostat/en/\#search/rice (accessed on 1 April 2020).

2. Cihan, A.; Kahveci, K.; Hacıhafızoglu, O. Modelling of intermittent drying of thin layer rough rice. J. Food Eng. 2007, 79, 293-298. [CrossRef]

3. Silva, W.P.; Precker, J.W.; Silva, C.M.D.P.S.; Silva, D.D.P.S. Determination of the effective diffusivity via minimization of the objective function by scanning: Application to drying of cowpea. J. Food Eng. 2009, 95, 298-304. [CrossRef]

4. Silva, W.P.; Precker, J.W.; Silva, C.M.D.P.S.; Gomes, J.P. Determination of effective diffusivity and convective mass transfer coefficient for cylindrical solids via analytical solution and inverse method: Application to the drying of rough rice. J. Food Eng. 2010, 98, 302-308. [CrossRef]

5. Kumar, C.; Karim, M.A.; Joardder, M.U.H. Intermittent drying of food products: A critical review. J. Food Eng. 2014, 121, 48-57. [CrossRef]

6. Golmohammadi, M.; Foroughi-dahr, M.; Rajabi-hamaneh, M.I.; Shojamoradi, A.; Hashemi, S. Study on drying kinetics of paddy rice: Intermittent drying. Iran. J. Chem. Chem. Eng.-Int. Engl. Ed. 2016, 35, 105-117.

7. Silva, W.P.; Galvão, I.B.; Silva, C.M.D.P.S.; Aires, J.E.F.; Figuêiredo, R.M.F. Empirical model for describing continuous and intermittent drying kinetics of apple pieces. Heat Mass Transf. 2020, 56, 1263-1274. [CrossRef]

8. Jung, H.; Yoon, W.B. The effect of intermittent drying on the cracking ratio of soybeans (Glycine max) at different relative humidity using reaction engineering approach modeling. Food Sci. Nutr. 2018, 6, 1492-1500. [CrossRef]

9. Elias, M.C.; Oliveira, M. Sistema Nacional de Certificação de Unidades Armazenadoras de Grãos e Fibras: Tecnologia e Legislação; Pelotas: Santa Cruz, Brazil, 2010; p. 477.

10. Silva, W.P.; Rodrigues, A.F.; Silva, C.M.D.P.S.; Castro, D.S.; Gomes, J.P. Comparison between continuous and intermittent drying of whole bananas using empirical and diffusion models to describe the processes. J. Food Eng. 2015, 166, 230-236. [CrossRef]

11. Cihan, A.; Ece, M.C. Liquid diffusion model for intermittent drying of rough rice. J. Food Eng. 2001, 49, 327-331. [CrossRef]

12. Silva, W.P.; Silva, C.M.D.P.S. LAB Fit Curve Fitting Software, V. 7.2.46. 2009. Available online: www.labfit.net (accessed on 1 April 2018).

13. Luikov, A.V. Analytical Heat Diffusion Theory; Academic Press, Inc. Ltd.: London, UK, 1968; p. 685.

14. Crank, J. The Mathematics of Diffusion; Clarendon Press: Oxford, UK, 1992; p. 414.

15. Silva, W.P.; Silva, C.M.D.P.S. Prescribed Adsorption-Desorption Software. 2009. Available online: http: //zeus.df.ufcg.edu.br/labfit/Prescribed.htm (accessed on 1 April 2018).

16. Faria, R.Q.; Teixeira, I.R.; Devilla, I.A.; Ascheri, D.P.R.; Resende, O. Cinética de secagem de sementes de crambe. Revista Brasileira de Engenharia Agrícola e Ambiental 2012, 16, 573-583. [CrossRef] 
17. Morais, S.J.S.; Devilla, I.A.; Ferreira, D.A.; Teixeira, I.R. Modelagem matemática das curvas de secagem e coeficiente de difusão de grãos de feijão-caupi (Vigna unguiculata (L.) Walp.). Revista Ciência Agronômica 2013, 44, 455-463. [CrossRef]

18. Santos, D.C.; Oliveira, E.N.A. Cinética de secagem de grãos de arroz-vermelho. Revista Acadêmica: Ciências Agrárias e Ambientais 2013, 11, 535-543.

19. Benseddik, A.; Azzi, A.; Zidoune, M.N.; Allafa, K. Mathematical empirical models of thin-layer airflow drying kinetics of pumpkin slice. Eng. Agric. Environ. Food 2018, 11, 220-231. [CrossRef]

20. Chua, K.J.; Mujumdar, A.S.; Chou, S.K. Intermittent drying of bioproducts-an overview. Bioresour. Technol. 2003, 90, 285-295. [CrossRef]

21. Kowalski, S.J.; Pawłowski, A. Energy consumption and quality aspect by intermittent drying. Chem. Eng. Process. Process Intensif. 2011, 50, 384-390. [CrossRef]

22. Lima, L.S.L.; Silva, W.P.; Pereira, J.C.A.; Gomes, J.P.; Silva, C.M.D.P.S.; Júnior, A.F.S. Description of continuous and intermittent drying of sapodilla with elimination of tempering period: Saving in drying time. Sylwan 2020, 164, 444-459.

23. Yang, Z.; Zhu, E.; Zhu, Z.; Wang, J.; Li, S. A comparative study on intermittent heat pump drying process of Chinese cabbage (Brassica campestris L. ssp) seeds. Food Bioprod. Process. 2013, 91, 381-388. [CrossRef]

24. Diamante, L.M.; Ihns, R.; Savage, G.P.; Vanhanen, L. A new mathematical model for thin layer drying of fruits. Int. J. Food Sci. Technol. 2010, 45, 1956-1962. [CrossRef]

25. Kaleta, A.; Górnicki, K. Evaluation of drying models of apple (var. McIntosh) dried in a convective dryer. Int. J. Food Sci. Technol. 2010, 45, 891-898. [CrossRef]

26. Costa, L.M.; Resende, O.; Sousa, K.A.; Gonçalves, D.N. Coeficiente de difusão efetivo e modelagem matemática da secagem de sementes de crambe. Revista Brasileira de Engenharia Agrícola e Ambiental 2011, 15, 1089-1096. [CrossRef]

27. Madamba, P.S.; Driscoll, R.H.; Buckle, K.A. Thin layer drying characteristics of garlic slices. J. Food Eng. 1996, 29, 75-97. [CrossRef]

(C) 2020 by the authors. Licensee MDPI, Basel, Switzerland. This article is an open access article distributed under the terms and conditions of the Creative Commons Attribution (CC BY) license (http://creativecommons.org/licenses/by/4.0/). 